\title{
Controlling Clostridium difficile
}

\section{SUMMARY}

Clostridium difficile infection causes colitis and is closely associated with the use of antimicrobials, probably due to disruption of the normal bowel flora.

Avoiding inappropriate antimicrobial use is the most important way to prevent this potentially life-threatening infection.

Emergent hypervirulent variants of $C$. difficile are associated with increased transmission, morbidity and mortality and have caused epidemics in North America and Europe. Cases have also been reported in Australia so intensified surveillance and antimicrobial stewardship is more important than ever.

While any antimicrobial can precipitate C. difficile, fluoroquinolones, clindamycin and cephalosporins are particularly implicated.

Other drugs, such as proton pump inhibitors, have also been associated with an increased incidence of $C$. difficile.

Severe disease is managed in hospital. For non-severe disease, treatment generally includes supportive measures and treatment with oral metronidazole. Relapse is common.

\section{Introduction}

Infection with the toxigenic anaerobe Clostridium difficile causes diarrhoea and colitis. Less commonly it causes toxic megacolon, colonic perforation and death. Disease is caused by two exotoxins - A and B which rank among the most potent bacterial toxins described.'

Older people with comorbidities are more often infected and have a poorer outcome. Risk factors for $C$. difficile infection are listed in Box 1.2-4 With the emergence of hypervirulent strains associated with increased mortality, $C$. difficile has moved from an uncommon hospital-acquired infection to a global public health concern.

C. difficile infection is closely associated with antimicrobial use. Consequently, any clinician who prescribes or dispenses antibiotics has an important role in preventing this potentially life-threatening and often avoidable infection.

\section{Epidemiology}

Although first described in 1935, the clinical importance of $\boldsymbol{C}$. difficile was not recognised until several patients died from fulminant colitis after receiving clindamycin in the 1970s. The incidence and severity of $C$. difficile has increased substantially in the last 20 years in the developed world. This trend is most prominent in elderly people in hospital and is increasingly recognised in residential aged-care facilities. In the USA, $C$. difficile is now the 18th leading cause of death in those over 65 years old. ${ }^{5}$

There is also an increased incidence of $C$. difficile infection outside of healthcare facilities. In a targeted surveillance program in Victoria, $16 \%$ of $C$. difficile cases were community-associated. ${ }^{6}$ Of cases identified in Queensland, 37\% had community-onset diarrhoea (unpublished data). Similarly, in surveys in the USA, up to $41 \%$ of cases were not associated with recent hospitalisation.?

In Australia, there is no published evidence of increasing incidence of $C$. difficile infection. However, until recently there was no uniform diagnostic approach or surveillance. ${ }^{8}$ In Victoria, between October 2010 and March 2011 there were 370 healthcare-associated cases (1.7 per 10000 occupied bed days). ${ }^{6}$

\section{Outbreaks of hypervirulent $C$. difficile}

In 2005 a novel strain of $C$. difficile, now known as PCR ribotype 027, led to an outbreak of severe diarrhoea and markedly increased mortality in hospitalised patients in Quebec, Canada. ${ }^{9}$ Cases were significantly more likely to have received fluoroquinolones, in particular moxifloxacin and

\section{Box 1 Risk factors for Clostridium difficile infection ${ }^{2 *}$}

Current or recent antimicrobial exposure (within 10 weeks)

Use of proton pump inhibitor or $\mathrm{H}_{2}$-receptor antagonist

Current or recent hospitalisation (within 2 months)

Chemotherapy

Older age

Medical comorbidities ${ }^{3}$

Previous $C$. difficile infection, especially relapsed disease

Use of diclofenac

* Up to $25 \%$ of community-acquired cases occur without established predisposing risk factors ${ }^{4}$ therefore stool testing should be considered for community-acquired diarrhoea

\section{Mark McFarlane \\ Registrar ${ }^{1}$ \\ Krispin Hajkowicz Infectious diseases physician' \\ Senior lecturer ${ }^{2}$ \\ Department of Infectious Diseases \\ Royal Brisbane and Women's Hospital \\ 2 School of Medicine University of Queensland Brisbane}

\section{Key words}

antibiotics, colitis, diarrhoea, infection

Aust Prescr 2013;36:121-4

First published online 16 May 2013 
gatifloxacin, than non-infected controls simultaneously admitted to the same hospital. PCR ribotype 027 produces additional virulence factors and is resistant to moxifloxacin.

There is increased transmission of PCR ribotype 027 in healthcare settings, with many large outbreaks resulting in frequent colectomies and high mortality in North America and Europe. Isolated, locally-acquired cases have also been reported in Australia. ${ }^{10}$

\section{Antimicrobial use and $C$. difficile}

Previous or current antimicrobial use is the major risk factor for $C$. difficile, although a minority of community cases have no history of antimicrobial prescription." Infection occurs when the normal colonic flora is disrupted by antimicrobials. This allows C. difficile to colonise the lumen of the large bowel and cause disease. Use of virtually any antibiotic may lead to $C$. difficile infection, although clindamycin, fluoroquinolones, penicillin beta-lactamase inhibitor combinations, amoxycillin and broad-spectrum cephalosporins are most frequently implicated. Curiously, even the mainstays of treatment for C. difficile - metronidazole and vancomycin - can precipitate $C$. difficile infection.

\section{Minimising the risk of infection}

Avoiding inappropriate antibiotic therapy prevents $C$. difficile in individual

\section{Avoiding inappropriate antibiotic therapy prevents $C$. difficile in individual patients}

patients. When antimicrobials are indicated, using the narrowest-spectrum drug for the shortest period is essential. Table 1 lists common clinical scenarios where antibiotic therapy may be avoided, or a narrow-spectrum drug selected.

Discussing the risk of $C$. difficile should be part of the consultation with any patient starting antibiotics. It can be raised in the difficult but common situation where a patient expects to be prescribed antibiotics when they are not indicated.
Antimicrobial stewardship programs using consensus guidelines, antimicrobial pre-approval, directed therapy based on culture results (where possible) and limiting the duration of intravenous and oral antimicrobials have been shown to decrease the incidence of $C$. difficile. ${ }^{12}$ The presence of an antimicrobial stewardship system is an Australian National Safety and Quality Health Service Standard. ${ }^{13}$

\section{Other drugs associated with C. difficile}

Proton pump inhibitors were associated with an increased risk of $C$. difficile (approximate risk ratio $=1.7$ ) in two meta-analyses. ${ }^{14,15}$ Concomitant use of antibiotics and proton pump inhibitors confers the highest risk. $\mathrm{H}_{2}$-receptor antagonists also increase the risk of $C$. difficile, but not to the same extent as proton pump inhibitors. Sometimes inappropriately used for 'peptic ulcer prophylaxis', up to $70 \%$ of proton pump inhibitor use in hospitals is outside recommended use. ${ }^{16}$ Judicious prescribing of these drugs within guidelines presents another important opportunity for prevention of $C$. difficile.

C. difficile has also been associated with several systemic antifungals, some cancer chemotherapies (such as doxorubicin and 5-fluorouracil), some immunosuppressants (such as methotrexate and cyclophosphamide) ${ }^{17}$ and the non-steroidal antiinflammatory drug diclofenac. ${ }^{18}$ These drugs all disrupt normal bowel flora.

\section{Diagnosis}

In a patient with signs and symptoms of infection, a single positive faecal immunoassay for toxin establishes the diagnosis of $C$. difficile. Testing should only be performed on an unformed stool sample. Different laboratories have varying testing algorithms. The majority of Australian laboratories perform enzyme immunoassays for toxins $A$ and $B .{ }^{19}$ Combined assays for toxins $A$ and $B$ have a high specificity, but more limited sensitivity ranging from 60 to $90 \%$. This means that a negative toxin result does not exclude

Table 1 Minimising the risk of Clostridium difficile in common clinical situations

\begin{tabular}{lll}
\hline Presentation & $\begin{array}{l}\text { Intervention with risk of causing } \\
\text { Clostridium difficile }\end{array}$ & More appropriate option \\
\hline Upper respiratory tract infection & Amoxycillin-clavulanate & $\begin{array}{l}\text { Patient education, good hydration and } \\
\text { simple analgesia }\end{array}$ \\
\hline Mild community-acquired pneumonia & Ceftriaxone & Amoxycillin \\
\hline $\begin{array}{l}\text { Asymptomatic bacteriuria outside } \\
\text { pregnancy }\end{array}$ & Cefalexin & Education and reassurance \\
\hline Cutaneous abscess less than $5 \mathrm{~cm}$ & Cefalexin & Incision and drainage \\
\hline Non-specific dyspepsia & Proton pump inhibitor & Careful evaluation of risks \\
\hline
\end{tabular}


infection. Submitting more than one stool sample for testing does not markedly improve sensitivity and is not recommended. ${ }^{20}$

Polymerase chain reaction-based assays have high sensitivity (93-97\%) ${ }^{21,22}$ and excellent specificity, but are expensive. Stool culture is too slow and laborious to be clinically useful, but is necessary to identify hypervirulent strains from a population health perspective.

Glutamate dehydrogenase stool antigen is a highly sensitive, but poorly specific, test for $\boldsymbol{C}$. difficile infection. It is increasingly used as an initial screening test in a diagnostic algorithm which also includes toxin assays and polymerase chain reaction. ${ }^{23}$

\section{Management}

Management of infection involves supportive measures and specific antibiotic therapy for $\mathrm{C}$. difficile. Where possible, any precipitating antecedent antimicrobials should be stopped. Although there is no evidence that stopping proton pump inhibitors prevents relapse or alters the outcome of $C$. difficile infection, ${ }^{15}$ they should be ceased if there is no strong indication. Antiperistaltic drugs such as opioids and loperamide should be avoided to reduce the risk of developing toxic megacolon. Oral fluid intake should be encouraged and rehydration solutions considered. The treatment of $C$. difficile depends on its severity.

\section{Non-severe disease}

Mild to moderate disease can be managed outside of hospital (see Box 2). Oral metronidazole $400 \mathrm{mg}$ three times a day for 10 days is recommended for an initial episode. In a randomised comparative study of patients with non-severe disease, $90 \%$ were cured with metronidazole and $98 \%$ with oral vancomycin. There was no significant statistical difference between treatment arms. ${ }^{24}$

\section{Severe disease}

Severe disease requires admission to hospital (Table 2). Surgical consultation, fluid resuscitation, and oral vancomycin are recommended. Guidelines for managing severe disease have been produced by the Australasian Society for Infectious Diseases. ${ }^{2}$

\section{Relapsing disease}

Relapses of colitis are seen in up to $25 \%$ of patients within four weeks of the end of treatment. ${ }^{25}$ The first recurrence should be treated in the same way as the initial episode (see Box 2). Subsequent recurrences should not be managed with metronidazole due to the risk of peripheral neuropathy with prolonged administration. A prolonged tapered course of vancomycin has been suggested for multiple relapses. Referral to an infectious disease specialist or gastroenterologist is recommended.

\section{Ancillary treatments}

Since disruption of normal flora is thought to be integral to the pathogenesis of infection, administration of probiotics to restore a symbiotic microbial flora has gained traction. Recent evidence suggests that commercially available probiotics containing Saccharomyces, Lactobacillus, Bifidobacterium and Streptococcus species moderately reduce the risk of relapse (relative risk 0.34).

Probiotics containing mixed species were marginally more effective than monomicrobial products.

Probiotics are well tolerated, making them particularly appealing. ${ }^{26,27}$

If more than one $C$. difficile relapse occurs and

the patient consents, donor faecal microbiota

\section{Box 2 Management of non-severe Clostridium difficille ${ }^{2}$}

\section{General measures}

Avoid or stop therapy with antiperistaltic drugs

Stop antibiotic therapy or use a narrow-spectrum antimicrobial if possible. If not, a prolonged course of treatment for $C$. difficile may be required.

Perform serial clinical assessment and include measurements of white cell count, creatinine and electrolytes

\section{Treatment of initial episode}

Metronidazole $400 \mathrm{mg}$ orally three times a day for 10 days

If unable to tolerate oral treatment, use metronidazole $500 \mathrm{mg}$ intravenously 8-hourly for 10 days

\section{Treatment of first recurrence}

As for initial episode

\section{Treatment of second or subsequent recurrence}

Vancomycin in a pulsed/tapering course (e.g. $125 \mathrm{mg}$ orally, four times a day for 14 days, then $125 \mathrm{mg}$ twice a day for 7 days, then $125 \mathrm{mg}$ every second day for 2-8 weeks; (other regimens also described)

Extracted and modified from: Cheng AC, Ferguson JK, Richards MJ, Robson JM, Gilbert GL, McGregor A, et al. Australasian Society for Infectious Diseases quidelines for the diagnosis and treatment of Clostridium difficile infection. Med J Aust 2011:194:353-358.

(c) Copyright 2011. The Medical Journal of Australia - reproduced with permission.

Table 2 Features suggesting severe Clostridium difficile infection ${ }^{2}$

\begin{tabular}{lll}
\hline Clinical features & Laboratory & Additional features \\
\hline Acute abdomen & White blood cell count $>15 \times 10^{9} / \mathrm{L}$ & Toxic megacolon \\
Fever $>38.5^{\circ} \mathrm{C}$ & Serum albumin $<25 \mathrm{mg} / \mathrm{L}$ & Pseudomembranes on \\
Hypotension & Elevated blood lactate & colonoscopy \\
Tachycardia & Acute kidney injury & \\
lleus & & \\
\hline
\end{tabular}




\section{SELF-TEST} QUESTIONS

True or false?

3. Treatment of an initial recurrence of Clostridium difficile should be with metronidazole.

4. A follow-up stool investigation for Clostridium difficile should be performed once the patient has recovered.

Answers on page 143 transplantation may be considered. In a randomised trial, faecal transplantation was associated with a substantially higher cure rate than oral vancomycin therapy $(94 \%$ vs $31 \%, p<0.001) .^{28}$

\section{Monitoring response to treatment}

Response to treatment is monitored with history and examination. The frequency of diarrhoea should start to decrease after about three days of treatment, and the patient should not have any feature of severe disease (fevers, rigors, peritonitis, toxic megacolon, ileus or haemodynamic instability). Routine follow-up stool examinations are not useful as a significant proportion of asymptomatic patients will have persistent stool carriage within 30 days of the end of treatment. $^{2}$

\section{Conclusion}

C. difficile is an emerging pathogen particularly in elderly people with comorbidities. So far, Australia has not seen extensive and prolonged outbreaks like those in North America and Europe. To maintain this position, clinical suspicion in cases of antibioticassociated diarrhoea, recognition of communityacquired $\mathrm{C}$. difficile and rigorous infection control are needed. Antimicrobial stewardship programs have been shown to reduce the incidence of $C$. difficile. This involves the judicious use of antimicrobials for approved indications only, and with the narrowest spectrum and shortest duration possible. Appropriate use of proton pump inhibitors and other drugs associated with $\mathrm{C}$. difficile will also help to prevent infection. Ensuring optimal prescribing will protect individual patients and the Australian community at large from this very important iatrogenic infection. $<$

\section{Dr Hajkowicz has received speaking honoraria from MSD.}

Acknowledgements: Dr Marion Woods for his helpful comments and corrections, Associate Professor Allen Chen for helpful advice, and Professor Paterson and Dr Charlotte Preston for providing unpublished data.

\section{REFERENCES}

1. Gill DM. Bacterial toxins: a table of lethal amounts. Microbiol Rev 1982;46:86-94

2. Cheng AC, Ferguson JK, Richards MJ, Robson JM, Gilbert GL, McGregor A, et al. Australasian Society for Infectious Diseases guidelines for the diagnosis and treatment of Clostridium difficile infection. Med J Aust 2011;194:353-8.

3. Loo VG, Bourgault AM, Poirier L, Lamothe F, Michaud S, Turgeon N, et al. Host and pathogen factors for Clostridium difficile infection and colonization. N Engl J Med 2011;365:1693-703.

4. Centers for Disease Control and Prevention. Surveillance for communityassociated Clostridium difficile - Connecticut, 2006. MMWR Morb Mortal Weekly Rep 2008;57:340-3.

5. Murphy SL, Xu JQ, Kochanek KD. Deaths: Preliminary data for 2010. National vital statistics reports; vol 60 no 4. Hyattsville, MD: National Center for Health Statistics; 2012.

6. Bull AL, Worth LJ, Richards MJ. Implementation of standardised surveillance for Clostridium difficile infections in Australia: initial report from the Victorian Healthcare Associated Infection Surveillance System. Intern Med J 2012;42:715-8.

7. Khanna S, Pardi DS, Aronson SL, Kammer PP, Orenstein R, St Sauver JL, et al. The epidemiology of community-acquired Clostridium difficile infection: a population-based study. Am J Gastroenterol 2012;107:89-95.

8. Stuart RL, Marshall C. Clostridium difficile infection: a new threat on our doorstep. Med J Aust 2011;194:331-2.

9. Loo VG, Poirier L, Miller MA, Oughton M, Libman MD, Michaud S, et al. A predominantly clonal multi-institutional outbreak of Clostridium difficileassociated diarrhea with high morbidity and mortality. N Engl J Med 2005;353:2442-9.

10. Richards M, Knox J, Elliott B, Mackin K, Lyras D, Waring LJ, et al. Severe infection with Clostridium difficile PCR ribotype 027 acquired in Melbourne, Australia. Med J Aust 2011;194:369-71.

11. Wilcox MH, Mooney L, Bendall R, Settle CD, Fawley WN. A case-control study of community-associated Clostridium difficile infection. J Antimicrob Chemother 2008;62:388-96.

12. Valiquette L, Cossette B, Garant M-P, Diab H, Pépin J. Impact of a reduction in the use of high-risk antibiotics on the course of an epidemic of Clostridium difficile-associated disease caused by the hypervirulent NAP1/027 strain. Clin Infect Dis 2007;45 Suppl 2:S112-21.

13. National Safety and Quality Health Service Standards. Sydney: Australian Commission on Safety and Quality in Health Care; 2011.

14. Kwok CS, Arthur AK, Anibueze Cl, Singh S, Cavallazzi R, Loke YK. Risk of Clostridium difficile infection with acid suppressing drugs and antibiotics: meta-analysis. Am J Gastroenterol 2012:107:1011-9.
15. Janarthanan S, Ditah I, Adler DG, Ehrinpreis MN. Clostridium difficileassociated diarrhea and proton pump inhibitor therapy: a meta-analysis. Am J Gastroenterol 2012;107:1001-10.

16. Molloy D, Molloy A, O’Loughlin C, Falconer M, Hennessy M. Inappropriate use of proton pump inhibitors. Ir J Med Sci 2010;179:73-5.

17. Mandell GL, Bennett JE, Dolin R. Mandell, Douglas, and Bennett's principles and practice of infectious diseases. 7th ed. Philadelphia, PA: Churchill Livingstone; 2010.

18. Suissa D, Delaney JA, Dial S, Brassard P. Non-steroidal anti-inflammatory drugs and the risk of Clostridium difficile-associated disease. Br J Clin Pharmacol 2012;74:370-5.

19. Ferguson JK, Cheng AC, Gilbert GL, Gottlieb T, Korman T, McGregor A, et al. Clostridium difficile laboratory testing in Australia and New Zealand: national survey results and Australasian Society for Infectious Diseases recommendations for best practice. Pathology (Phila) 2011;43:482-7.

20. Cardona DM, Rand KH. Evaluation of repeat Clostridium difficile enzyme immunoassay testing. J Clin Microbiol 2008;46:3686-9.

21. Huang $\mathrm{H}$, Weintraub A, Fang $\mathrm{H}$, Nord $\mathrm{CE}$. Comparison of a commercial multiplex real-time PCR to the cell cytotoxicity neutralization assay for diagnosis of clostridium difficile infections. J Clin Microbiol 2009;47:3729-31.

22. Peterson LR, Manson RU, Paule SM, Hacek DM, Robicsek A, Thomson RB Jr, et al. Detection of toxigenic Clostridium difficile in stool samples by real-time polymerase chain reaction for the diagnosis of $C$. difficile-associated diarrhea. Clin Infect Dis 2007;45:1152-60.

23. Sharp SE, Ruden LO, Pohl JC, Hatcher PA, Jayne LM, Ivie WM. Evaluation of the C.Diff Quik Chek Complete Assay, a new glutamate dehydrogenase and $\mathrm{A} / \mathrm{B}$ toxin combination lateral flow assay for use in rapid, simple diagnosis of clostridium difficile disease. J Clin Microbiol 2010;48:2082-6.

24. Zar FA, Bakkanagari SR, Moorthi KM, Davis MB. A comparison of vancomycin and metronidazole for the treatment of Clostridium difficile-associated diarrhea, stratified by disease severity. Clin Infect Dis 2007;45:302-7.

25. Louie TJ, Miller MA, Mullane KM, Weiss K, Lentnek A, Golan Y, et al. Fidaxomicin versus vancomycin for Clostridium difficile infection. N Engl J Med 2011;364:422-31.

26. Pillai A, Nelson R. Probiotics for treatment of Clostridium difficile-associated colitis in adults. Cochrane Database Syst Rev 2008;1:CD004611.

27. Johnston BC, Ma SS, Goldenberg JZ, Thorlund K, Vandvik PO, Loeb M, et al. Probiotics for the prevention of Clostridium difficile-associated diarrhea: a systematic review and meta-analysis. Ann Intern Med 2012;157:878-88.

28. van Nood E, Vrieze A, Nieuwdorp M, Fuentes S, Zoetendal EG, de Vos WM, et al. Duodenal infusion of donor feces for recurrent Clostridium difficile. N Engl J Med 2013;368:407-15. 